Journal of Physical Science, Vol. 28(1), 129-156, 2017

\title{
Chemical Kinetics and Reaction Mechanisms in Solvent Extraction: New Trends and Applications
}

\author{
Naglaa E. El-Hefny \\ Hot Laboratories Center, Atomic Energy Authority, 13759 Cairo, Egypt \\ E-mail: neelhefny@hotmail.com
}

Published online: 15 April 2017

To cite this article: El-Hefny, N. E. (2017). Chemical kinetics and reaction mechanisms in solvent extraction: New trends and applications. J. Phys. Sci., 28(1), 129-156, https://doi.org/10.21315/jps2017.28.1.10

To link to this article: https://doi.org/10.21315/jps2017.28.1.10

\begin{abstract}
Solvent extraction is a technique used to separate compounds based on their solution preferences in two different immiscible liquids. Chemical kinetics is the area of science devoted to study the rates as well as the mechanisms of reactions. This review deals with the basics of chemical kinetics and reaction mechanisms in solvent extraction technique, new trends and chemical kinetics applications as well as the projections to the future.
\end{abstract}

Keywords: Extraction, kinetics, techniques, reaction rate, mechanism

\section{INTRODUCTION}

Solvent extraction separation is based on the difference in the solubilities of elements and their compounds in two immiscible liquid phases. The transfer of components in liquid-liquid extraction across an interface can be subdivided into three steps. The components are initially transported to the interface, then they cross the interface and are finally transported away from the interface. Chemical kinetics are concerned with the quantitative study of the rates of chemical reactions and the factors upon which they depend. The factors affecting the chemical kinetics include empirical studies of the effects of concentration, temperature and hydrostatic pressure on reactions of different types. It also provides the most general methods for determining the mechanism of a given reaction; this in turn explains its reaction rate. ${ }^{1-3}$ 
Equilibria can also be treated in principle on the basis of kinetics in the situation in which the rates of the forward and reverse reactions are equal. The main purpose for studying chemical kinetics is to learn as much as possible about the steps involved in a reaction in order to get information on the factors affecting the extraction rate and propose a mechanism describing the extraction process. This series of steps is called the reaction mechanism. ${ }^{3}$ On the other hand, as the advanced technological applications require particles with specific characteristics size, morphology and composition and spot the light on the type of agitation by using the Lewis-cell which allowed the formation of homogeneous emulsions and minimised the breakage of crystals which occurs with a mechanical stirrer.

\section{REACTION RATE}

Reaction rate is the rate of change of concentration of a substance involved in the reaction per unit time. ${ }^{2}$ Chemical kinetics deal with the speed at which these changes occur. The speed of a process is defined as the change in a given quantity over a specific period of time. For chemical reactions, the quantity that changes is the amount or concentration of a reactant or product. So the reaction rate of a chemical reaction is defined as the change in concentration of a reactant or product per unit time: ${ }^{3}$

Rate $(k)=\frac{\text { Concentration of } A \text { at time } t_{2}-\text { Concentration of } A \text { at time } t_{1}}{t_{2}-t_{1}}$

$k=-\left[\frac{d A}{d t}\right]$

where $A$ represents a specific reactant or product and the square brackets indicate concentration in mol $\mathrm{l}^{-1}$. The rate constant $k$ is also known as the specific reaction rate or as the rate coefficient and it is numerically equal to the reaction rate when the reactants are present at unit concentrations. ${ }^{2}$

The order of the reaction is the sum of the exponents of concentration factors in an experimental rate law. ${ }^{4}$ In the kinetic study, reactions are usually classified according to the order of reaction. As a zero-order reaction depends on one molecule, when no concentration term affects the rate of reaction, or the rate of reaction remains same throughout the reaction, the reaction is known as zero-order reaction. ${ }^{5}$ One of the most widely encountered kinetic forms is that of the first-order rate equation, where the rate is directly proportional to the concentration of one reactant. The effective kinetic order is reduced to the reaction order with respect to that one substance. If the order is unity, the reaction is said to follow pseudo-first- 
order kinetics. While the second-order kinetics arises when it is proportional to the square of the concentration of a single reagent and also when it is proportional to the product of the concentrations of two reagents. A third-order reaction can result from the reaction of a single reactant, two reactants or three reactants. ${ }^{5}$

\subsection{Rate Controlling Extraction Regimes}

The kinetics of solvent extraction is a function of both the various chemical reactions occurring in the system and the rates of diffusion of the various species that control the chemistry of the extraction process. ${ }^{6}$ Solvent extraction kinetics can be controlled only by slow chemical reactions or by diffusion through the interfacial films. When one or more of the chemical reactions is sufficiently slow (slow distribution of the predominant species between the aqueous phase and the interface), in comparison with the rate of diffusion to and away from the interface of the various species taking part in an extraction reaction, in this case the solvent extraction kinetics occurs in a kinetic regime. In this case, the extraction rate can be described in terms of chemical reactions taking place either in the bulk phase or at the interface. ${ }^{6}$ Based on the two films theory, Danesi proposed a model in which he assumed the presence of two stagnant thin layers of finite thickness on the aqueous and organic sides of the interface, shown in Figure 1.7

ORGANIC PHASE

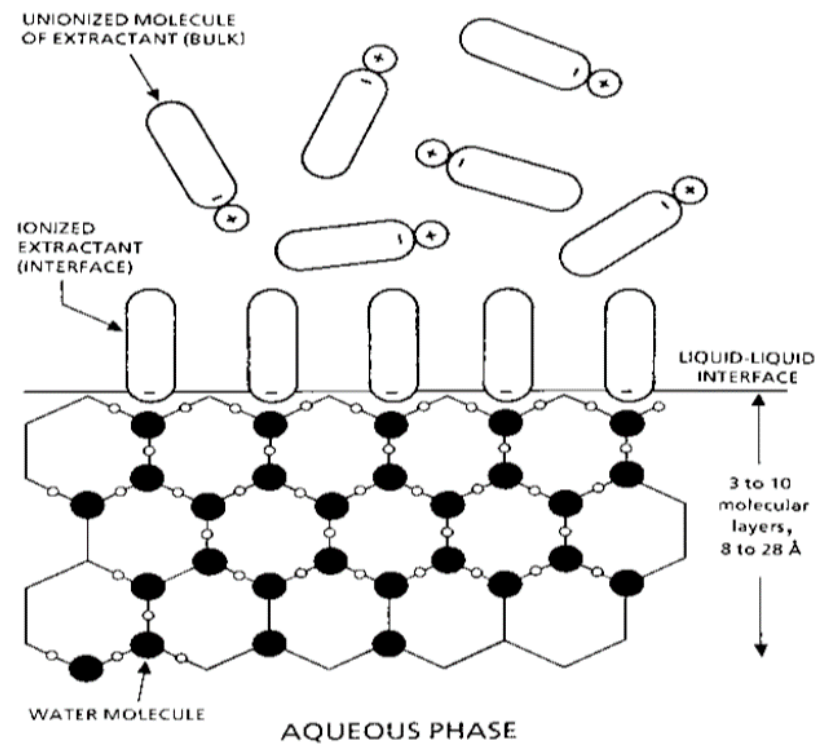

Figure 1: Interfacial structuring effect caused by an ionisable extractant adsorbed at the organic-aqueous interface. ${ }^{7}$ 
When the extractant has low surface activity and a relatively high solubility in the aqueous phase, the reaction takes place in the aqueous phase. ${ }^{7-9}$ In case where the extractant is relatively soluble and the reaction is neither controlled by the diffusion process nor by any reaction at the interface. When the reaction occur at the interface, the transport of molecules from one phase to the other occurs even without mechanical agitation of the two phases..$^{10}$ In this case, the interfacial reaction is the rate-determining step in extraction, acceleration in the rate of agitation of the two phases enhances the extraction. . $^{10,11}$

However, when all chemical reactions in the biphasic system are very fast in comparison with the diffusional processes, the solvent extraction kinetics is said to occur in a diffusional regime, where the rate of extraction can be described simply in terms of interfacial film diffusion. The thickness of the diffusion films never go down to zero and a limiting thickness of about $10^{-3}-10^{-4} \mathrm{~cm}$ is reached in all systems even with the most efficiently stirred systems. ${ }^{12}$ These diffusion films are very thin and never less than $10^{-4} \mathrm{~cm}$. They are considered macroscopic compared with dimensions of the molecules that pass through them. On the other hand, when both chemical reactions and film diffusion processes occur at comparable rates, the solvent extraction kinetics is said to take place in a mixed diffusional-kinetic regime, which in engineering, is often referred to as "mass transfer with slow chemical reactions." This is the most complicated case, since the rate of extraction must be described in terms of both diffusional processes and chemical reactions, and a complete mathematical description can be obtained only by simultaneously solving the differential equations of diffusion and those of chemical kinetics. ${ }^{11,12}$

\section{IDENTIFICATION OF REACTION MECHANISM}

In order to distinguish between a diffusional regime and a kinetic regime, the criteria usually used are the dependency of the rate of extraction on the stirring rate of the two phases as well as the evaluation of the activation energy of extraction based on the temperature effect.

\subsection{Stirring Rate Dependence}

The controlling process is usually determined by the effect of stirring speed. In diffusion controlled systems, the rate of extraction increases with the increase of the rate of stirring while in the case of chemical reactions (kinetic regime) there is nearly no stirring effect on the rate of extraction. A typical curve of rate of extraction vs. stirring rate is shown in Figure 2; such curves are generally obtained 
when constant interfacial-area-stirred cells (Lewis cells) and vigorously mixed flasks are used. In general, a process occurring under the influence of diffusional contributions is characterised by an increase of the rate of extraction, as long as the stirring rate of the two phases is increased. On the other hand, when the rate of extraction is independent of the stirring rate, it is sometimes possible to assume that the extraction process occurs in a kinetic regime. ${ }^{6}$

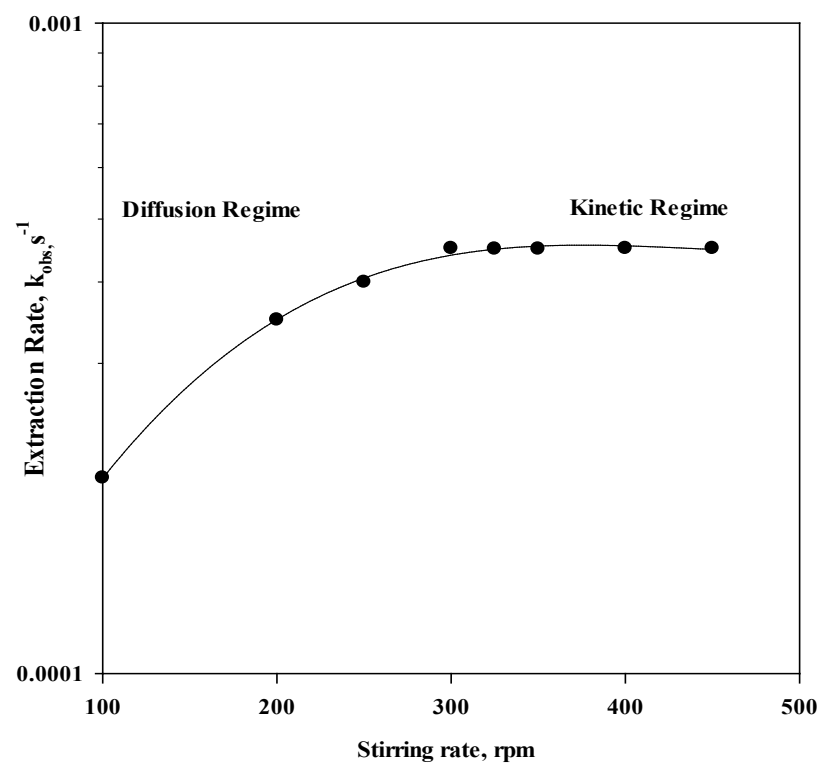

Figure 2: Typical extraction rate vs. stirring rate for constant interfacial-area stirred cell.

\subsection{Activation Energy}

In the study of chemical kinetics, the reaction rate constants were functions of temperature. The activation energy of a reaction is the difference in energy of the activated complex and the reactants. On the other hand, the temperature effect on the rate of extraction controlled by diffusion is less pronounced than that controlled by the chemical process and the activation energy in the former case does not usually exceed $20.9 \mathrm{~kJ} \mathrm{~mol}^{-1} .^{13}$ When the rate is controlled by a chemical reaction, the activation energy is generally higher than that expected for a diffusion-controlled process. However, this criterion is not always very meaningful, since many chemical reactions occurring in solvent extraction processes exhibit activation energies of less than this value and may be of only a few kilojoules per mole, i.e., in the same order of magnitude as those of diffusion processes. ${ }^{6}$ 
It was found that an experimental plot of $\ln k$ vs. $1 / T$ appeared to be approximately linear with a negative slope obeying the Arrhenius equation:

$$
k_{o b s}=A e^{-E / R T}
$$

where $R$ is the universal gas constant, $T$ the absolute temperature, and $A$ the preexponential factor or frequency factor. The activation energy $E$ was calculated from the slope of this line indicating that, the extraction is controlled by diffusion reaction or chemical reaction. ${ }^{6}$

\section{IDENTIFICATION BETWEEN KINETIC REACTION IN THE BULK PHASE OR AT THE INTERFACE}

As one or more reaction steps of the overall reaction mechanism, either occurring in the bulk phase (homogenous reaction) or at the liquid-liquid interface (heterogeneous reaction), are slow enough, their slowness will reflect on the overall rate of extraction. ${ }^{6}$ The effect of interfacial area is the parameter usually used to differentiate between chemical reactions taking place in the bulk phase or at the interface. For interfacial chemical control, the interfacial area will be important together with the interfacial activity of the extractant. For bulk phase reactions the most important kinetic parameters are the reactants solubility.

\subsection{Interfacial Area}

In the bulk reactions, the rate of extraction is independent of the interfacial area, while in the case of interfacial reactions the rate of extraction increases with increasing interfacial area. In systems controlled by chemical reaction at the interface, the observed reaction rate constant increases linearly with specific interfacial area $\bar{a}$ ( $\bar{a}=$ interfacial area $\mathrm{Q} /$ volume of the phase $\mathrm{V}$ ), while no effect is observed on $\bar{a}$ in systems controlled by reactions in the bulk phase. ${ }^{6}$ The values of the rate of extraction $\mathrm{k}$ increase with the increase of the specific interfacial area $\bar{a}$ giving a straight line which passes through the origin indicating that the rate of extraction is dependent on the variation in interfacial area and the rate controlling reaction takes place at the interface rather than in the bulk phase. ${ }^{15}$ The rate-determining step of the extraction reaction is the interfacial formation of the complex between the metal ion and the interfacially adsorbed extracting reagent. There are two interfacial rate-determining steps, consisting of: ${ }^{6}$

1. Formation of an interfacial complex between the interfacially adsorbed molecules of the extractant and the metal ion. 
2. Transfer of the interfacial complex from the interface to the bulk organic phase and simultaneous replacement of the interfacial vacancy with bulk organic molecules of the extractant.

For this mechanism, we distinguish two possibilities. The first describes the reaction with the dissociated anion of the extracting reagent. The second describes the reaction with the undissociated extractant.

\subsection{Interfacial Tension}

Interfacial tension studies are particularly important because they can provide useful information on the interfacial concentration of the extractant. The simultaneous hydrophobic-hydrophilic (low water affinity-high water affinity) nature of extracting reagents has the resulting effect of maximising the reagent affinity for the interfacial zone, in which both the hydrophobic and hydrophilic parts of the molecules can minimise their free energy of solution. ${ }^{6}$ The interfacial tension is one of the fundamental physical properties of liquid/liquid interface. It is defined as the force per unit length that is required to increase the contact surface of two immiscible liquids of $1 \mathrm{~cm}^{2}$. The units of the interfacial tension are dyne $\mathrm{cm}^{-1}$. It determines the droplet form and the force retaining the droplet and reflects the interfacial concentration of substances directly. The relation between the interfacial tension $(\gamma)$ and the interfacial concentration of a substance $(\Gamma)$ is expressed as the following Gibbs adsorption isotherm: ${ }^{15,16}$

$\mathrm{d} \gamma=\sum_{\mathrm{i}} \Gamma_{\mathrm{i}}^{\sigma} \mathrm{d} \mu_{\mathrm{i}}$

where $\mu_{\mathrm{i}}$ refers to the chemical potential of component (i) at interface $(\sigma)$.

The surface activity of the extractant lends support to an extraction mechanism governed by interfacial chemical reactions. The decrease in the interfacial tension with the increase in the extractant concentration indicates that the extractant is interfacially adsorbed and produces a lowering of the organic-aqueous interfacial tension. ${ }^{6,17,18}$ Among these extractants we can mention tributyl phosphate (TBP) and crown ethers.

\subsection{Solubility of the Extractant}

When the extractants have low surface activity and relatively high solubility in the aqueous phase, the controlling reaction is expected to take place in the bulk of the aqueous phase. Thenoyltrifluoroacetone (HTTA) and di-ethylhexyl phosphoric acid (HDEHP) are among the extractants having relatively high solubility in 
the aqueous phase and the rate of extraction using these extractants are usually controlled by chemical reactions in the aqueous phase rather than in the interface. The nature of the diluents used also affects the rate of extraction, where the aromatic diluents cause swelling of the interfacial layers; they decrease the concentration of the extractant molecules at the interface which decreases the extraction rate. The addition of $20 \%$ of aromatic substances to kerosene as an aliphatic hydrocarbon, change its properties and make it similar to aromatic hydrocarbon. ${ }^{19,20}$

\section{CHEMICAL KINETICS TECHNIQUES}

Several experimental techniques are available for measuring the kinetics of solvent extraction. They differ in the different efficiency of stirring which can be achieved in the two phases, and in the control of the hydrodynamic conditions in proximity to the interface and in the interfacial area. ${ }^{21}$

\subsection{Rotating Diffusion Cell}

In this technique, a filter soaked with an organic phase solution is located between an organic phase and an aqueous phase. When only the filter is rotated, convection and a stagnant layer are formed at each side of the filter. In this case, the transport process of a substance from the aqueous phase to the organic phase consists of three steps: the diffusion of the substance in the aqueous stagnant layer to the filter; its transfer through the interface; and its diffusion in the organic stagnant layer. ${ }^{22}$ This method can divide the whole transport process into the diffusion process and the mass transfer process through the interface, but it does not evaluate the amount of substance adsorbed at the interface. Recently, there are few investigations using this technique.

\subsection{High Speed Stirring Technique}

A phase separator with poly(tetrafluoroethylene) (PTFE) membrane can take out only the organic phase from the container even when the two-phase solutions are stirred vigorously. ${ }^{24}$ Liquid membranes combine extraction and stripping, which are normally carried out in two separate steps in conventional processes such as solvent extraction into one step. When a substance of interfacial absorptivity is dissolved in the organic phase and the interfacial area becomes wider by vigorous stirring, the substance concentration in the organic phase decreases according to the principle of mass balance. This method also allows to measure extraction rate by adding a reactant during stirring. Recently, detailed mechanism of the 
complexation reaction at the heptane/water or toluene/water interface was proved in the solvent extraction of metal ions. ${ }^{24-26}$

\subsection{Single Drop Technique}

This technique includes the formation of a single organic droplet in an aqueous phase solution by micro-injection method. The absorbance of the organic droplet increases when the extraction of a substance from the aqueous phase to the organic droplet proceeds. The increasing rate gives the mass transfer rate of the substance through the interface indirectly. The ion-pair extraction rate of a cationic dye (Methylene Blue) with dodecylsulfate anion to a single droplet of tributyl phosphate was investigated by this method..$^{27,28}$ They also proposed mass transfer mechanism through the interface by analysing the rate with a concept of spherical diffusion.

\subsection{Two-Phase Microchip Technique}

The extraction of a dye (Methyl Red) at a cyclohexane/water interface was investigated by two-phase microchip method, where Methyl Red was extracted from the aqueous phase to the cyclohexane phase..$^{29}$ A two-phase microchip was made by microchip technique. In this technique, the two phases met at a position and they flowed adjacently in parallel with each other with the same linear velocity.

\subsection{Constant Interfacial-Area-Stirred Cell}

When an organic phase and an aqueous phase are allowed to stand naturally, a horizontal and flat liquid/liquid interface is formed between the two phases. In this technique, the two phases are stirred while the aqueous and the organic layers are individually stirred without disturbing the interface and the transfer occurs through the contact area. ${ }^{30,31}$ The cells allow an independent change of the rotation number of the stirrers in the two phases. The organic and aqueous phases can be stirred in the same direction to have similar fluid dynamic conditions. This technique was first developed by Lewis ${ }^{30}$ then modified by several investigators, ${ }^{32}$ but it is not suitable for very slow reactions.

\section{NEW TRENDS IN KINETIC STUDIES}

The kinetics of solvent extraction, which is of high importance to all industrial applications, is largely determined by the interfacial chemistry. To speed up phase transfer, the engineers try to maximise the interfacial surface by, e.g., violent 
stirring, producing billions of small droplets. ${ }^{33}$ The largest research effort in extraction kinetics is likely to be in the development of solvent extraction-related techniques, such as various versions of liquid chromatography, liquid membranes, etc. These techniques require a detailed knowledge about the kinetics of the system to predict the degree of separation..$^{34}$

Future development has been focused on microscopic spectroscopy of an nmresolution, synthesis of novel two-dimensional substances specific to the interface, invention of analytical methods clarifying the nature and dynamics of interfacial aggregates or associates are expected for improving the investigations of the chemical changes taking place at the liquid/liquid interfaces. ${ }^{35}$

\subsection{Kinetics of Redox Reactions}

Kinetic studies are important to learn about the different variables affecting the extraction rate of metal ions and identify the controlling regime. Lewis cell technique is the simplest one preferred by many investigators for carrying out kinetic investigations. ${ }^{21,36-45}$ Several metal or metalloid ions exist in multiple oxidation states and can undergo electron transfer reactions that are important in biological and environmental systems. ${ }^{46}$ There are endogenous metal ions such as iron, copper, and cobalt that participate in oxidation-reduction reactions with species of oxygen like molecular dioxygen, superoxide, and hydrogen peroxide.

Kinetic studies of the forward extraction of trivalent $\mathrm{Nd}(\mathrm{III})$ by the commercial trioctylphosphine oxide (CYANEX 921) in kerosene from thiocyanate medium and stripping of Nd-CYANEX 921 chelate have been investigated using a Lewis cell. ${ }^{14}$ The different parameters affecting the extraction rate were separately studied. The experimental results demonstrated that, the rate of $\mathrm{Nd}$ (III) extraction is controlled by a chemical reaction at the interface rather than in the bulk phase and it is first order for CYANEX 921 concentration, while it is zero order with respect to the other investigated parameters. Kinetic parameters of iron oxide reduction by hydrogen were evaluated by the isothermal method in a differential micro-packed bed. ${ }^{49}$ Influence of external diffusion, internal diffusion and heat transfer on the intrinsic reaction rate was investigated and the conditions free of internal and external diffusion resistance have been determined. In the experiments, in order to evaluate the kinetic parameters for reducing $\mathrm{Fe}_{2} \mathrm{O}_{3}$ to $\mathrm{Fe}_{3} \mathrm{O}_{4}$, the reaction temperatures were set between $440^{\circ} \mathrm{C}$ and $490^{\circ} \mathrm{C}$. However, in order to distinguish the reduction of $\mathrm{Fe}_{3} \mathrm{O}_{4}$ to $\mathrm{FeO}$ from that of $\mathrm{FeO}$ to $\mathrm{Fe}$, the reaction temperature in the experiment was set to be greater than $570^{\circ} \mathrm{C}$; kinetics of iron oxide reduction by hydrogen was established and the newly established kinetic models were validated by the experimental data. The kinetics of the oxygen reduction reaction on nanostructured 
thin-film ternary $\mathrm{Pt} / \mathrm{Co} / \mathrm{Mn}$ catalyst was investigated in $50 \mathrm{~cm}^{2}$ proton-exchange membrane single cell fixtures. ${ }^{48}$

The kinetic data were derived from cell polarisation curves measured during Galvan dynamic scans from near open-circuit to a high current density and back to near open-circuit. The kinetic data were correlated with a single Tafel equation and a transfer coefficient that is a function of the relative humidity. Traditionally, $\mathrm{Cr}(\mathrm{VI})$ is removed from water through reduction of $\mathrm{Cr}(\mathrm{VI})$ to $\mathrm{Cr}(\mathrm{III})$ using a reducing agent such as ferrous sulfate, sulfur dioxide, or sodium disulfite, followed by precipitation as $\mathrm{Cr}(\mathrm{III})$ or elemental iron. ${ }^{49-54}$ During the last 12 years the usage of permeable reactive barriers using iron for the remediation of groundwater contaminated with chromium (VI) has became widespread. After the reduction by the elemental iron, the $\mathrm{Cr}$ (III) precipitates as hydroxide or as oxihydroxide, allowing its removal. ${ }^{55-59}$

Zero valent iron has been extensively used as a reactive medium for the reduction of $\mathrm{Cr}(\mathrm{VI})$ to $\mathrm{Cr}(\mathrm{III})$ in reactive permeable barriers. ${ }^{60}$ The kinetic rate depends strongly on the superficial oxidation of the iron particles used and the preliminary washing of zero valent iron increases the rate. The reaction has been primarily modelled using a pseudo-first-order kinetics which is inappropriate for a heterogeneous reaction. Kinetic studies were performed in order to evaluate the suitability of this approach. The influence of the following parameters was experimentally studied. The assumed order for the reaction was confirmed. In addition, the rate constant was calculated from the data obtained in different operating conditions.

Kinetics of reaction between palladium(II) chloride complex and dimethylamineborane was investigated. ${ }^{61}$ Experiments were carried out at various initial concentrations of palladium(II) complex ions and reductant, ionic strengths and temperatures. Rate constants of the reaction were determined. The rate law as well as mechanism of the reaction were also presented. The reaction was found to be second-ordered in respect to $\mathrm{PdCl}_{4}$ and pseudo-first ordered in respect to DMAB. The kinetics of reduction with $\mathrm{CH}_{4}, \mathrm{H}_{2}$ and $\mathrm{CO}$ and oxidation with $\mathrm{O}_{2}$ of two NiO-based oxygen-carriers for chemical-looping combustion and chemicallooping reforming prepared by impregnation, $\mathrm{NiO}_{18} \mathrm{Al}$ and $\mathrm{NiO}_{21} \mathrm{Al}$, have been determined. ${ }^{62}$ The kinetic data obtained could be used for the design of chemicallooping combustion and chemical-looping reforming systems.

\subsubsection{Kinetics of oxidative stripping}

The novel work carried out in our laboratories has been directed to study the forward extraction kinetics of $\mathrm{Cu}$ (II) from nitrate medium using CYANEX 302 in 
kerosene and kinetics of oxidative stripping of $\mathrm{Cu}(\mathrm{I})$-CYANEX 302 chelate using a Lewis cell. ${ }^{13}$ The slow reaction between the copper ion with $\left(H A_{2}\right)_{\bar{i}}$ with the release of one hydrogen ion is expected to be the rate determining step:

$$
C u^{2+}+\left(H A_{2}\right)^{\bar{i}} \underset{k-1}{\stackrel{k_{i}}{\rightleftarrows}}\left(C u A_{2}\right)_{i}+H^{+} \quad \text { Slow }
$$

And, the extraction rate is given by the following equation:

$$
k_{o b s}=\bar{a} k_{1} K_{D} K_{d} \frac{\left[\overline{H_{2} A_{2}}\right]}{H^{+}}-\bar{a} k_{-1} \frac{\left[\left(C u A_{2}\right)\right]_{i}\left[H^{+}\right]}{C u^{2+}}
$$

Kinetic studies on the stripping of $\mathrm{Cu}(\mathrm{I})$ from loaded CYANEX 302 with high concentration of nitric acid were also carried out using the same Lewis cell.

Copper is first extracted as $\mathrm{Cu}^{2+}$ then a reduction of the extracted species $\left[\overline{\mathrm{Cu} \mathrm{A}_{2}(H A)_{2}}\right]$ converts the copper to its monovalent state $\mathrm{Cu}(\mathrm{I}){ }^{14}$

$\left[\overline{\mathrm{CuA}_{2}(H A)_{2}}\right] \stackrel{k_{1}}{\rightleftarrows}\left[\overline{\mathrm{CuA}(H A)_{2}+A^{-}}\right]$

The interfacial chemical reaction between the adsorbed species and $\mathrm{HNO}_{3}$ which re-oxidise the monovalent copper ion in the organic phase to its divalent state in the aqueous via a slow rate-determining step.

$$
\left[\overline{\mathrm{CuA}_{2}(H A)_{2}}\right]_{i}+2 \mathrm{HNO}_{3} \underset{k_{-1}}{\stackrel{k_{1}}{\rightleftarrows}}\left[\mathrm{Cu}\left(\mathrm{NO}_{3}\right)_{2} H A\right]_{i}+\left[(H A)_{2}\right]_{i}+H^{+} \quad \text { Slow (6) }
$$

Finally, the rate of forward stripping reaction can be represented by the following equation:

$$
\text { Rate }=k_{s t p}=\bar{a} k_{1}\left[H N O_{3}\right]^{2}
$$

\subsection{Kinetics of Extraction with Saponified Extractants}

The extraction and separation of $\mathrm{Mn}$ (II) and $\mathrm{Co}$ (II) from sulphate solutions have been carried out using sodium salts of D2EHPA, 2-ethylhexyl phosphonic acid mono-2-ethylhexylester (PC 88A) and CYANEX 272 in kerosene. ${ }^{63}$ Manganese was preferentially extracted over cobalt with these extractants and Na-D2EHPA was found to be the most suitable extractant for separation. The extraction and separation of divalent zinc and manganese from a sulphate solution was performed using sodium salts of the same aforementioned extractants dissolved in kerosene. ${ }^{64}$ 
Liquid-liquid extraction of aluminium(III) from sulphate medium using sodium salt of Cyanex 272 and D2EHPA in kerosene has been studied. ${ }^{65}$ Maximum Al(III) extraction was achieved in the equilibrium $\mathrm{pH}$ range of 3.2-3.6 and 3.5-4.2 for Na-Cyanex 272 and Na-D2EHPA, respectively. Both extractants can quantitatively and selectively extract $\mathrm{Al}(\mathrm{III})$ from a mixed solution of aluminium, cobalt and nickel. Solvent extraction experiments of $\mathrm{Nd}$ with $40 \%$ saponified PC88A from chloride solution have been performed. ${ }^{66}$ The use of saponified PC88A significantly increased the distribution coefficients of Nd, compared with the case where PC88A was used. The variations in the equilibrium $\mathrm{pH}$ value were greatly dependent on the initial extraction conditions. Through our work, a new trend of kinetics of Sm(III) extraction from an aqueous chloride solution using CYANEX 272 dissolved in kerosene after being converted to sodium salt has been performed. ${ }^{67}$

\subsection{Kinetics of Stripping by Precipitation}

The optical, electronic, and magnetic properties of materials change dramatically when the particle size is reduced to a critical limit. The preparation and investigation of size-confined materials down to the nanometer scale have been one of major academic research and industrial focus in recent years. ${ }^{68-72}$ Rare earths and yttrium formulated as metal oxide powders are used in a variety of advanced technological applications. Most of these applications require particles with specific characteristics: size, morphology and composition. Solvent extraction systems are used routinely in hydrometallurgy in the primary processing and purification operations of these elements. ${ }^{73-76}$ Copper ions have been extracted by an organic extractant and oxalic acid-ethanol aqueous solution has been employed to strip and precipitate copper. ${ }^{77}$ The copper precipitates have been characterised by $\mathrm{x}$-ray diffractometry, scanning electron microscopy, transmission electron microscopy and laser particle analyser.

The processes of uranium stripping from 30\% tri-n-butyl phosphate (TBP) in kerosene by $\mathrm{H}_{2} \mathrm{O}_{2}$ solutions both with and without $\mathrm{NH}_{4} \mathrm{OH}$ added were investigated in the temperature range of $20^{\circ} \mathrm{C}-50^{\circ} \mathrm{C}$. The uranium was selectively precipitated in the form of uranium peroxide during stripping from the organic phase by hydrogen peroxide. The effect of hydrogen peroxide on the organic phase was studied by IR spectroscopy. ${ }^{78}$ The organic cerium deposits were obtained by a stripping precipitation method from cerium-loaded P507 organic phase using oxalic acid as a precipitating agent and nano-sized ceria particles were prepared by calcining the products at $500^{\circ} \mathrm{C} .{ }^{79}$ Separation of palladium from high level liquid waste (HLLW) solution originated from the reprocessing of spent fuel by PUREX process is carried out by solvent extraction and precipitation methods using oximes. The loaded organic phase is scrubbed with water prior to the stripping of palladium 
using thiourea in $\mathrm{HNO}_{3}$ and $\mathrm{NH}_{4} \mathrm{OH}$ separately. ${ }^{80}$ The recovery of the method is found to be $>99.5 \%$.

Recently, a type of agitation by using the Lewis-cell allowed the formation of homogeneous emulsions and minimised the breakage of crystals which occurs with a mechanical stirrer. In this concern, the solvent extraction process of neodymium(III) from aqueous solution by di(2-ethylhexyl) phosphoric acid (HDEHP) in kerosene has been performed as a first step to accomplish the homogeneous precipitation of neodymium phosphate by stripping from an organic metal loaded HDEHP solution using phosphoric acid solutions. ${ }^{85}$ In this study, stripping-precipitation approach was proposed to synthesise powders of neodymium phosphate using a modified Lewis cell. The neodymium precipitate was characterised by x-ray diffractometry, scanning electron microscopy, particle size measurement, thermogravimetric analysis and infrared spectroscopy.

IR spectrum of the resulted neodymium phosphate powder was carried out with the result shown in Figure 3. The spectrum shows the hydrogen bonding band at 3475 $\mathrm{cm}^{-1}$ for $\mathrm{H}_{2} \mathrm{O}$ molecules the $-\mathrm{OH}$ bending band at $1626 \mathrm{~cm}^{-1}$, the $\mathrm{P}-\mathrm{O}$ stretching band at $1047 \mathrm{~cm}^{-1}$ and $\mathrm{P}-\mathrm{OH}$ stretching band in the region from 1200 to 1090 $\mathrm{cm}^{-1}$ for the phosphoric acid. None of the HDEHP characteristic bands appears in the phosphate powder. Hence, HDEHP is behaving as a true mediator in the formation of the phosphate precipitate. The thermal analysis (DTA-TG) curves of the neodymium phosphate powder show an endothermic peak with average $11.1 \%$ weight loss probably due to the dehydration of water of crystallisation between $194^{\circ} \mathrm{C}$ and $214^{\circ} \mathrm{C}$.

The DSC analysis (Figure 4) shows endothermic peak lying in the same range of temperature degrees which confirm the results obtained from DTA-TG analysis. The particle morphology of the surface of neodymium phosphate precipitate was studied by scanning electron micrograph Figure 5. The results showed that the powder precipitated with $3 \mathrm{M} \mathrm{H}_{3} \mathrm{PO}_{4}$ showed more regular and slightly larger particles than those obtained by $5 \mathrm{M} \mathrm{H}_{3} \mathrm{PO}_{4}$ while the precipitate with $8 \mathrm{M} \mathrm{H}_{3} \mathrm{PO}_{4}$ gave highly agglomerated particles. Increasing the HDEHP concentration from $0.25 \mathrm{M}$ to $0.75 \mathrm{M}$ gave an increase of the particle size of the precipitate. 


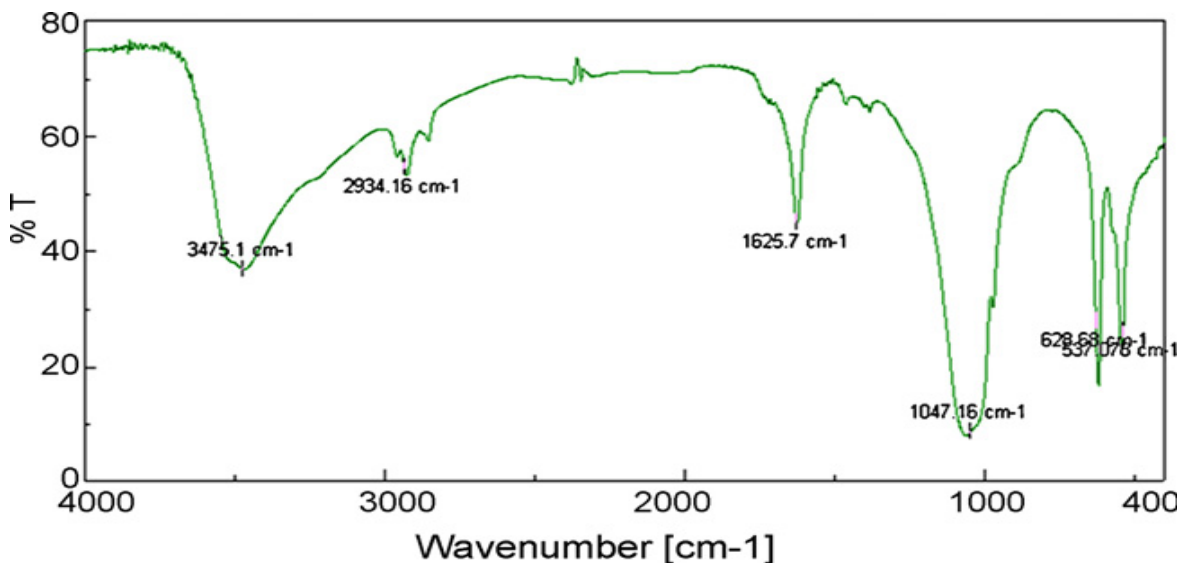

Figure 3: IR spectrum of neodymium phosphate powder precipitated from $0.083 \mathrm{M}$ $\mathrm{Nd}(\mathrm{III}), 0.5 \mathrm{M}$ HDEHP with $5 \mathrm{M} \mathrm{H}_{3} \mathrm{PO}_{4}$ solution at $\mathrm{pH}=0.5$.

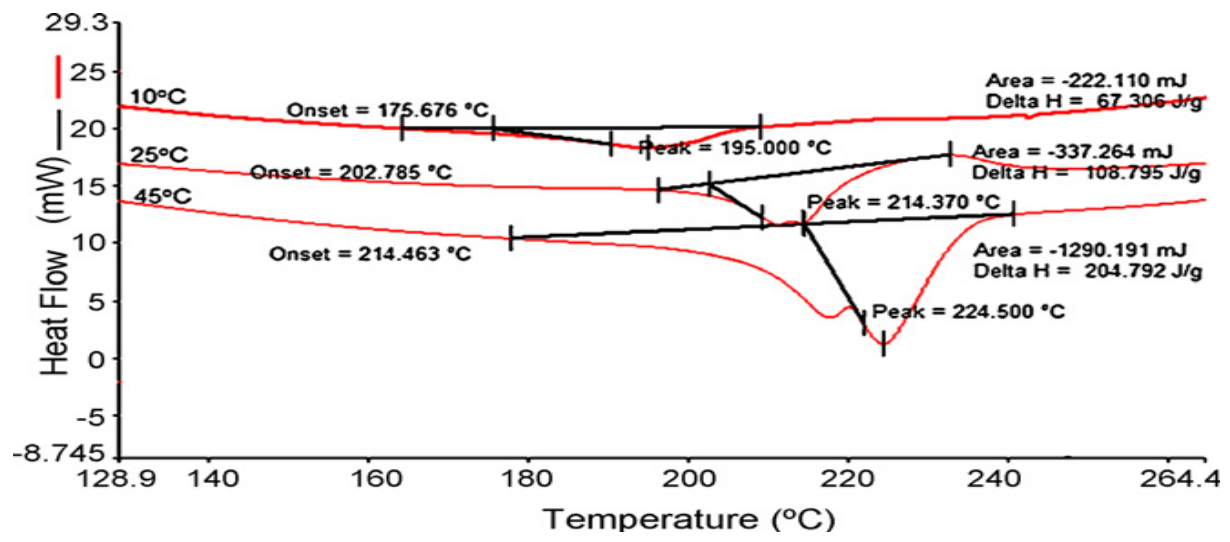

Figure 4: DSC of Nd phosphate powder at different temperature degrees.
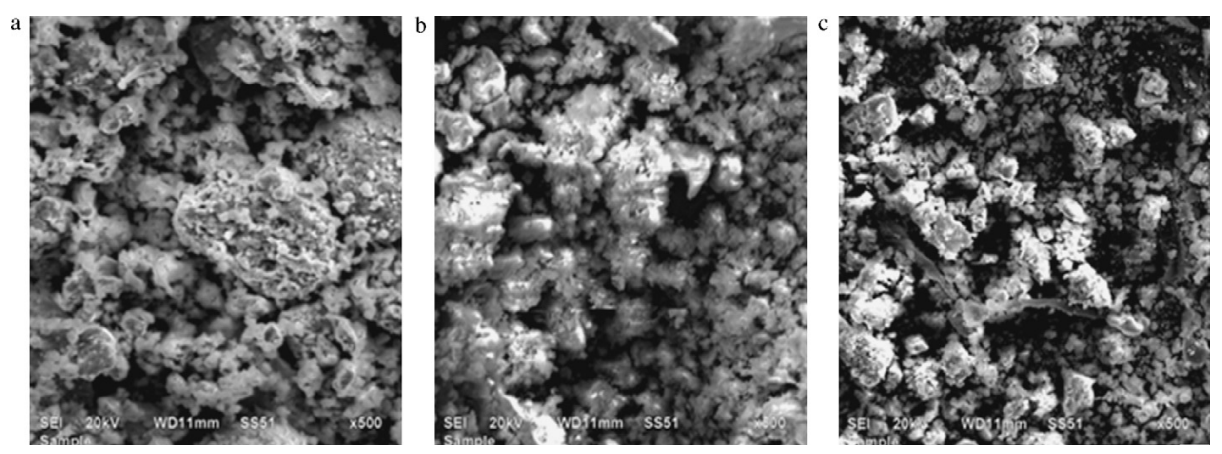

Figure 5: Scanning electron microscopic examination on the resulted $\mathrm{Nd}$ phosphate powder by stripping with $5 \mathrm{M} \mathrm{H}_{3} \mathrm{PO}_{4}$ at $25^{\circ} \mathrm{C}$ from loaded HDEHP, illustrating (a) 0.25M HEDHP, (b) 0.5M HDEHP, and (c) 0.75M HDEHP. 


\section{CHEMICAL KINETICS APPLICATIONS}

The mathematical models that describe chemical reaction kinetics provide chemists and chemical engineers with tools to better understand and describe chemical processes such as treatment of radioactive and industrial waste solutions, food decomposition, microorganism growth, stratospheric ozone decomposition, and the complex chemistry of biological systems. These models can also be used in the design or modification of chemical reactors to optimise product yield, more efficiently separate products, and eliminate environmentally harmful by-products. When performing catalytic cracking of heavy hydrocarbons into gasoline and light gas, for example, kinetic models can be used to find the temperature and pressure at which the highest yield of heavy hydrocarbons into gasoline will occur.

\subsection{Separation of Metals from Industrial and Radioactive Waste}

Management of radioactive waste generated during the operation of nuclear facilities, in medicine, industry and other fields is an important problem implicating further development of nuclear technology and nuclear energy worldwide. Due to its harmfulness, the radioactive waste cannot be directly discharged into the environment. It must be pre-sorted and processed to reduce the volume of radioactive substances in the smallest possible volume enabling stabilisation and then long-term storage or final disposal. ${ }^{82}$ In these processes one of the desirable features of extraction is speed, defined in terms of rates of extraction. In this context, the kinetics of solvent extraction systems offer information on the overall mass transfer and allows the prediction of inhibitions and enhancements on the extraction rate. In addition, exploitation of the differences in the reaction kinetics of metal ions could be used for their separation..$^{83,84}$

In the nuclear industry, important volumes of liquid wastes have to be treated to reduce their contents in radioactive contaminants. The co-precipitation is the method mostly applied to perform decontamination of liquid wastes which cannot be concentrated by evaporation. Two operating modes are typically used for an industrial scale treatment by coprecipitation: the continuous and the semi-batch process. It was proved experimentally and theoretically that the semi-batch reactor ensures decontamination efficiency much higher than the continuous stirred tank reactor. ${ }^{85}$

A successful leaching procedure of phosphogypsum (PG), a byproduct from acidulation of the phosphate rock by the wet process phosphoric acid, has been developed in the present work. This was possible through leaching of radionuclides by using TBP-TOPO in kerosene. The best leach ability percent obtained of Ra, 
$\mathrm{Pb}, \mathrm{U}, \mathrm{K}$ and REE from PG was reached by the synergism of TBP-TOPO in kerosene through two successive steps respectively. The extracted radionuclides can be easily recovered from the solvent and introduced in many useful processes. The best conditions for the stripping of radioactive materials using of $\mathrm{Na}_{2} \mathrm{CO}_{3}$ were aqueous: organic phase ratio of $2: 1$ for $9 \min ^{86}$

Wastes produced from nuclear and industrial activities contain large amounts of hazardous heavy metals whose recovery from waste streams is great importance. Recently, membrane technology has become an important alternative to the normal processes usually used for separation and recovery of undesired materials. They are used on large scale in water treatment for drinking water and industrial purposes and wastewater purification. . $^{61,87-90}$ The individual permeation of $\mathrm{Co}(\mathrm{II})$ and $\mathrm{Ni}$ (II) from aqueous chloride solutions through SLM using CYANEX 301 in kerosene as carrier supported on cellulose acetate membrane has been studied..$^{91}$ The results are used to assess the conditions for maximum recovery of heavy metals from aqueous chloride solutions and from water effluents of different origins.

\subsection{Radioactive Isotopes}

In contrast to chemical equilibria, chemical reaction rates depend on the concentration of the reactants and transition states but not on the product. The concentration of the transition states depends on the activation energy for its formation and the frequency for its decomposition into the products. For isotopes of the lighter elements, the activation energy term makes the main contribution to the reaction rate isotope effect, while for the heavier elements the vibrational frequency causing the decomposition into the products plays the larger role. Because the energy states usually are more separated for the isotopic molecules of the products and reactants than for the transition state, isotope effects are usually larger in reaction kinetics than in equilibria. Studies of kinetic isotope effects are of considerable theoretical interest, particularly in organic chemistry. The practical applications are still meager, but this will not necessarily be so in the future. An example is the decrease in metabolic rate for ${ }^{13} \mathrm{C}$ compounds, which has led to the suggestion of its use for treatment of certain diseases, as e.g., porphyria. ${ }^{90}$

\subsection{Food Decomposition}

In order to maximise glucose production from non-food cellulosic raw materials, data on the kinetics of cellulose decomposition and formation rates of end products are required. Glucose decomposition is a complex reaction system that has often been modelled with empirical, simplified models. ${ }^{91}$ By comparing the extraction yields of vitamin $C, \beta$-carotene, aloin $A$ and astaxanthin in different foods with that 
in microwave assisted extraction and solvent extraction, the chemical kinetics of vitamin $\mathrm{C}$ and aloin $\mathrm{A}$, which composed two different steps including the extraction step of analyte transferred from matrix into solvent and the decomposition step of analyte degraded in the extraction solvent, were proposed. ${ }^{92}$

\subsection{Catalysis}

Some of the most important concepts of the kinetics of complex heterogeneous catalytic reactions, methodology of building kinetic models and mathematical treatment of experimental data, influence of heat and mass transfer, types of laboratory reactors, kinetics and nanosized catalysts and others are reported. Examples for use of the kinetic studies for the development and application of industrial catalysts and modeling of industrial reactors are presented. ${ }^{93-96}$

\subsection{Ozone Decomposition}

The room temperature kinetics of gas-phase ozone loss via heterogeneous interactions with thin alumina films has been studied in real-time using $254 \mathrm{~nm}$ absorption spectroscopy to monitor ozone concentrations. ${ }^{97}$ The initial uptake coefficients on fresh films were found to be inversely dependent on the ozone concentration, varying from $10^{-6}$ for ozone concentrations of $10^{14}$ molecules $/ \mathrm{cm}^{3}$ to $10^{-5}$ at $10^{13}$ molecules $/ \mathrm{cm}^{3}$. These coefficients were not dependent on the relative humidity, up to $75 \%$, within the precision of the experiment. The decomposition of ozone in water is found to be second order at $\mathrm{pH} 2$ and 4 with the rate insensitive to $\mathrm{pH}$. At $\mathrm{pH} 6$, the reaction order is $3 / 2$ to 2 and at $\mathrm{pH} 8$ it is first order. Above $\mathrm{pH} 6$ the rate increases rapidly with $\mathrm{pH}$. Ozonation can greatly reduce the organic matter in waste water. ${ }^{98}$

\subsection{Complex Chemistry of Biological Systems}

Dynamic mathematical models in biotechnology require, besides the information about the stoichiometry of the biological reaction system, knowledge about the reaction kinetics. ${ }^{99}$ Modeling the kinetics of the processes that represent a biophysical system has long been pursued with the aim of improving our understanding of the studied system. Due to the unique properties of biological systems, in addition to the usual difficulties faced in modeling the dynamics of physical or chemical systems, biological simulations encounter difficulties that result from intrinsic multiscale and stochastic nature of the biological processes. ${ }^{100}$ 


\section{PROJECTIONS TO THE FUTURE}

It would be useful to have extractants available in kinetic systems to use below the $\mathrm{pH}$ of the hydrolysis of some metals such as iron. More extractants for application to nuclear waste may also appear. With further research, the organic degradation should be understood and overcome. Additionally, the reduction in the reaction time and the operating cost should be emphasised by accepting the technology that has been proven scientifically. Some of the new advances which are used in conventional solvent extraction and may be extended to chemical kinetics studies include the treatment of nuclear wastes, additional metals and by-product recovery to obtain very high purity metals. On the other hand, the increased treatment of waste dusts and scrap for recycling is important particularly the treatment of effluents for contaminant removal to meet environmental requirements.

One of the important industrial tasks is related to the esters which play a significant role in daily living and chemical industry, such as plasticisers, fragrance, adhesive and lubricants. The vast majority of esters can be prepared using esterification reaction in the chemical engineering industry. Therefore, various esterification mechanisms should be proposed for homogeneous and heterogeneous systems. Based on the mechanism, numerous kinetic models could be developed to represent the kinetic behaviours of esterification.

\section{SUMMARY}

- Solvent extraction separation is based on the difference in the solubilities of elements and their compounds in two immiscible liquid phases

- Chemical kinetics is the area of science devoted to study the rates as well as the mechanisms of reactions

- Reaction rate is the rate of change of concentration of a substance involved in the reaction per unit time

- The kinetics of solvent extraction, which is of high importance to all industrial applications, is largely determined by the interfacial chemistry

- The mathematical models that describe chemical reaction kinetics provide chemists and chemical engineers with tools to better understand and describe chemical processes. These models can also be used in the design or 
modification of chemical reactors to optimise product yield, more efficiently separate products, and eliminate environmentally harmful by-products

- Rare earths and yttrium formulated as metal oxide powders are used in a variety of advanced technological applications. Most of these applications require particles with specific characteristics: size, morphology and composition

- Ester is one of the important industrial tasks which play a significant role in daily living and chemical industry

\section{REFERENCES}

1. Watarai, H., Teramae, N. \& Sawada, T. (2011). Interfacial nanochemistry. New York: Springer.

2. Yeremin, E. N. (1979). The foundation of chemical kinetics. Moscow: MIR Publishers.

3. Zumdahl, S. S. (2007). Chemical principles, 6th ed. New York: Cengage.

4. Espenson, J. H. (1981). Chemical kinetics and reaction mechanisms. New York: McGraw-Hill.

5. Upadhyay, S. K. (2006). Chemical kinetics and reaction dynamics. Springer: New York.

6. Rydberg, J., Musikas, C. \& Choppin, G. R. (2004). Solvent extraction principles and practice, 2nd ed. New York: CRC, https://doi. org/10.1201/9780203021460.

7. Danesi, P. R., Chirizia, R. \& Coleman, C. F. (1980). The kinetics of metal solvent extraction. Crit. Rev. Anal. Chem., 10(1), 1-126, https://doi. org/10.1080/10408348008085494.

8. Aly, H. F. \& Daoud, J. A. (1996). Overview on extraction kinetics of metal adducts. J. Radioanal. Nucl. Ch., 208(1), 47-74, https://doi.org/10.1007/ BF02039749.

9. Fishman, A. J., Finston, H. L. \& Goldberg, D. E. (1973). Further studies of the rate affected synergic solvent extraction of Fe(III)-TTA-I: The effect of tri-n-octylphosphine oxide on the solvent extraction of iron(III) with 2-thenoyltrifluoroacetone. J. Inorg. Nucl. Chem., 35(7), 2497-2505, https:// doi.org/10.1016/0022-1902(73)80317-3.

10. Sekine, T. \& Hasegawa, Y. (1977). Solvent extraction chemistry. New York: Marcel Dekker. 
11. Danesi, P. R., Chiarizia, R. \& Vandergrift, G. F. (1980). Kinetics and mechanism of the complex formation reactions between copper(II) and iron(III) aqueous species and a .beta.-hydroxy oxime in toluene. J. Phys. Chem., 84(25), 3455-3461, https://doi.org/10.1021/j100462a030.

12. Danesi, P. (1992). Principles and practices of solvent extraction. New York: Marcel Dekker.

13. El-Hefny, N. E. (2010). Kinetics and mechanism of extraction of $\mathrm{Cu}(\mathrm{II})$ by CYANEX 302 from nitrate medium and oxidative stripping of $\mathrm{Cu}(\mathrm{I})$ using Lewis cell technique. Chem. Eng. Process., 49(1), 84-90, https://doi. org/10.1016/j.cep.2009.11.012.

14. El-Hefny, N. E. (2007). Kinetics and mechanism of extraction and stripping of neodymium using a Lewis cell. Chem. Eng. Process., 46(7), 623-629, https://doi.org/10.1016/j.cep.2006.08.007.

15. Kato, R. et al. (2004). Thiourea-isothiouronium conjugate for strong and selective binding of very hydrophilic $\mathrm{H}_{2} \mathrm{PO}_{4}-$ anion at the 1,2-dichloroethane-water interface. Tetrahedr. Lett., 45(22), 4273-4276, https://doi.org/10.1016/j.tetlet.2004.04.001.

16. Yulizar, Y., Ohashi, A. \& Watarai, H. (2001). Kinetic complexation mechanisms of $\mathrm{Ni}$ (II) and $\mathrm{Zn}$ (II) with a pyridylazo-ligand at liquid-liquid interfaces. Anal. Chim. Acta., 447(1-2), 247-254, https://doi.org/10.1016/ S0003-2670(01)01286-7.

17. Adamson, A. W. (1982). Physical chemistry of surfaces. New York: John Wiley \& Sons.

18. Davies, J. T. \& Rideal, E. K. (1961). Interfacial phenomena. New York: Academic Press.

19. Szymanowski, J. \& Tondre, C. (1994). Kinetics and interfacial phenomena in classical and micellar extraction systems. Solvent Extr. Ion Exc., 12(4), 873-905, https://doi.org/10.1080/07366299408918243.

20. Szymanowski, J., Prochaska, K. \& Alejski, K. (1990). Interfacial behavior of LIX $65 \mathrm{~N}$ and surface kinetics of copper extraction. Hydrometal., 25(3), 329-348, https://doi.org/10.1016/0304-386X(90)90048-7.

21. Tsukahara, S. (2006). Recent analytical methodologies on equilibrium, kinetics, and dynamics at liquid/liquid interface. Anal. Chim. Acta, 556(1), 16-25, https://doi.org/10.1016/j.aca.2005.05.050.

22. Albery, W. J. et al. (1976). Interfacial transfer studied with a rotating diffusion cell. J. Chem. Soc. Farad., 72, 1618-1626, https://doi.org/10.1039/ f19767201618.

23. Watarai, H. \& Freiser, H. (1983). Role of the interface in the extraction kinetics of zinc and nickel ions with alkyl-substituted dithizones. J. Am. Chem. Soc., 105(2), 189-190, https://doi.org/10.1021/ja00340a007. 
24. Ohashi, A. \& Watarai, H. (2001). Direct spectrophotometric measurements of acid-catalyzed complexation of palladium(II) with 2-(5-Bromo-2pyridylazo)-5-diethylaminophenol at the heptane/water interface by a centrifugal liquid membrane method. Anal. Sci., 17(11), 1313-1320, https:// doi.org/10.2116/analsci.17.1313.

25. Yulizar, Y., Monjushiro, H. \& Watarai, H. (2004). Interfacial aggregate growth process of $\mathrm{Fe}(\mathrm{II})$ and $\mathrm{Fe}(\mathrm{III})$ complexes with pyridylazophenol in solvent extraction system. J. Colloid Interf. Sci., 275(2), 560-569, https:// doi.org/10.1016/j.jcis.2004.02.045.

26. Oyama, H., Ohashi, A. \& Watarai, H. (2004). Complex formaton of copper(II) and iron(II) with octadecyloxythiazolylazophenol at the heptanwater interface. Anal. Sci., 20(11), 1543-1548, https://doi.org/10.2116/ analsci.20.1543.

27. Chikama, K., Negishi, T. \& Nakatani, K. (2003). Transfer mechanism of dodecyl sulfate with methylene blue across an oil/water interface studied by single-droplet injection and microabsorption methods. Bull. Chem. Soc. Jap., 76(2), 295-299, https://doi.org/10.1246/bcsj.76.295.

28. Chikama, K., Negishi, T. \& Nakatani, K. (2004). Extraction of tributyltin and triphenyltin across a single oil droplet/water interface. Anal. Chim. Acta, 514(2), 145-150, https://doi.org/10.1016/j.aca.2004.03.063.

29. Surmeian, M. et al. (2002). Three-layer flow membrane system on a microchip for investigation of molecular transport. Anal. Chem., 74(9), 2014-2020, https://doi.org/10.1021/ac0112317.

30. Lewis, J. B. (1954). The mechanism of mass transfer of solutes across liquid-liquid interfaces: Part I: the determination of individual transfer coefficients for binary systems. Chem. Eng. Sci., 3(6), 248-259, https://doi. org/10.1016/0009-2509(54)80007-8.

31. Danesi, P. R. et al. (1982). Armollex: An apparatus for solvent extraction kinetic measurements. Sep. Sci. Technol., 17, 961-968, https://doi. org/10.1080/01496398208082106.

32. Kislik, V. S. (2012). Solvent extraction: Classical and novel approaches. London: Elsevier.

33. Daoud, J. A. (2004). Overview on the liquid-liquid extraction mechanisms of uranium from aqueous solutions. Proceedings of the Eighth Conference of Nuclear Sciences and Applications, vol. 1, Cairo, Egypt, 7-12 February, 1.

34. Vandegrift, G. F. \& Horwitz, E. P. (1977). The mechanism of interfacial mass transfer of calcium in the system: Di(2-ethylhexyl)phosphoric acid in dodecane-dilute nitric acid. J. Inorg. Nucl. Chem., 39(8), 1425-1432, https:// doi.org/10.1016/0022-1902(77)80310-2. 
35. Biswas, R. K. \& Mondal, G. K. (2003). Kinetics of Mn(II) extraction by D2EHPA. Hydrometal., 69(1-3), 145-156.

36. Lim, T. M. et al. (1996). Kinetics studies of solvent extraction of rare earths into DEHPA. Proceedings of the International Solvent Extraction Conference (ISEC'96), March 19-23, Melbourne, Australia, 1, 445.

37. El-Dessouky, S. I., Daoud, J. A. \& Aly, H. F. (1999). Mechanism of the synergistic extraction of octahedral $\mathrm{Co}$ (II) from nitrate medium by 8-hydroxyquinoline-Db18C6 chloroform mixture. Radiochim. Acta, 85(12), 79-82, https://doi.org/10.1524/ract.1999.85.12.79.

38. Dongbei, W., Ying, X. \& Deqian, L. (2006). Mass transfer kinetics of yttrium(III) using a constant interfacial cell with laminar flow. Part I. Extraction with cyanex 302. Hydrometal., 82(3-4), 176-183.

39. Wionczyka, B. et al. (2011). Studies on the kinetics and equilibrium of the solvent extraction of chromium(III) from alkaline aqueous solutions of different composition in the system with Aliquat 336. J. Hazard. Mater., 198, 257-268, https://doi.org/10.1016/j.jhazmat.2011.10.038.

40. Wang, X., Meng, S. \& Li, D. (2010). Extraction kinetics of ytterbium(III) by 2-ethylhexylphosphonic acid mono-(2-ethylhexyl) ester in the presence of isooctanol using a constant interfacial cell with laminar flow. Sep. Purif. Technol., 71(1), 50-55, https://doi.org/10.1016/j.seppur.2009.11.001.

41. El-Dessouky, S. I., El-Hefny, N. E. \& Daoud, J. A. (2004). Studies on the equilibrium and mechanism of Th(IV) extraction by CYANEX 272 in kerosene from nitrate medium. Radiochim. Acta, 92(1), 25-30, https://doi. org/10.1524/ract.92.1.25.25409.

42. Niemczewska, J., Cierpiszewski, R. \& Szymanowski, J. (2003). Extraction of zinc(II) from model hydrochloric acid solutions in Lewis cell. Physicochem. Prob. Min. Process., 37, 87-96.

43. Wu, D., Wang, X. \& Li, D. (2007). Extraction kinetics of Sc(III), Y(III), $\mathrm{La}(\mathrm{III})$ and Gd(III) from chloride medium by Cyanex 302 in heptane using the constant interfacial cell with laminar flow. Chem. Eng. Process., 46(1), 17-24, https://doi.org/10.1016/j.cep.2006.04.007.

44. Abdel Rahman, N., Daoud, J. A. \& Aly, H. F. (2003). Mechanism of uranium(IV) extraction with CYANEX 302 in kerosene from nitrate medium. J. Radioanal. Nucl. Ch., 258(3), 597-603, https://doi.org/10.1023/ B:JRNC.0000011756.77475.17.

45. El-Nadi, Y. A., El-Hefny, N. E. \& Daoud, J. A. (2003). Mechanism of extraction of hexavalent uranium from alkaline medium by aliquat-336/ kerosene solution. J. Nucl. Radiochem. Sci., 4(2), 19-22, https://doi. org/10.14494/jnrs2000.4.19.

46. Carter, D.E. (1995). Oxidation-reduction reactions of metal ions. Environ. Health Perspect., 103 (Suppl 1): 17-19. 
47. Hou, B. et al. (2012). Study on kinetics of iron oxide reduction by hydrogen. Chem. Eng. J., 20(1), 10-17, https://doi.org/10.1016/s1004-9541(12)603577.

48. Ahluwalia, R. K. et al. (2012). Kinetics of oxygen reduction reaction on nanostructured thin-film platinum alloy catalyst. J. Power Sourc., 215(1), 77-88, https://doi.org/10.1016/j.jpowsour.2012.04.077.

49. Erdem, M. et al. (2005). Hexavalent chromium removal by ferrochromium slag. J. Hazard. Mater., 126(1-3), 176-182, https://doi.org/10.1016/j. jhazmat.2005.06.017.

50. Guha, S. \& Bhargava, P. (2005). Removal of chromium from synthetic plating waste by zero-valent iron and sulfate-reducing bacteria. Water Environ. Res., 77(4), 411-416, https://doi.org/10.2175/106143005X51996.

51. Gheju, M. \& Lovi, A. (2006). Kinetics of hexavalent chromium reduction by scrap iron. J. Hazard. Mater., 135(1-3), 66-73, https://doi.org/10.1016/j. jhazmat.2005.10.060.

52. Hu, J., Lo, I. M. C. \& Chen, G. (2007). Comparative study of various magnetic nanoparticles for Cr(VI) removal. Sep. Purif. Technol., 56(3), 249-256, https://doi.org/10.1016/j.seppur.2007.02.009.

53. Erdem, M. \& Tumen, F. (2004). Chromium removal from aqueous solution by the ferrite process. J. Hazard. Mater., 109(1-3), 71-77, https://doi. org/10.1016/j.jhazmat.2004.02.031.

54. Altundogan, H. S. (2005). Cr(VI) removal from aqueous solution by iron (III) hydroxide-loaded sugar beet pulp. Process Biochem., 40(3-4),14431452, https://doi.org/10.1016/j.procbio.2004.06.027.

55. Mukhopadhyay, B., Sundquist, J. \& Schmitz, R. J. (2007). Removal of $\mathrm{Cr}(\mathrm{VI})$ from Cr-contaminated groundwater through electrochemical addition of Fe(II). J. Environ. Manage., 82(1), 66-76, https://doi.org/10.1016/j. jenvman.2005.12.005.

56. Blowes, D. W., Ptacek, C. J. \& Jambor, J. L. (1997). In-situ remediation of $\mathrm{Cr}(\mathrm{VI})$-contaminated groundwater using permeable reactive walls: Laboratory studies. Environ. Sci. Technol., 31(12), 3348-3357, https:// doi.org/10.1021/es960844b.

57. Chang, L. Y. (2005). Chromate reduction in wastewater at different $\mathrm{pH}$ levels using thin iron wires - a laboratory study. Environ. Prog., 24, 305316, https://doi.org/10.1002/ep.10082.

58. Melitas, N., Chuffe-Moscoso, O. \& Farrell, J. (2001). Kinetics of soluble chromium removal from contaminated water by zerovalent iron media: Corrosion inhibition and passive oxide effects. Environ. Sci. Technol, 35(19), 3948-3953, https://doi.org/10.1021/es001923x. 
59. Yang, J. E. et al. (2007). Mechanistic evidence and efficiency of the $\mathrm{Cr}(\mathrm{VI})$ reduction in water by different sources of zerovalent irons. Water Sci. Technol., 55(1-2), 197-202, https://doi.org/10.2166/wst.2007.062.

60. Fiúza, A. et al. (2010). Heterogeneous kinetics of the reduction of chromium (VI) by elemental iron. J. Hazard. Mater., 175(1-3), 1042-1047, https://doi. org/10.1016/j.jhazmat.2009.10.116.

61. Wojnicki, M. et al. (2011). Kinetics of palladium(II) chloride complex reduction in aqueous solutions using dimethylamineborane. Hydrometal., 110(1-4), 56-61, https://doi.org/10.1016/j.hydromet.2011.08.006.

62. Dueso, C. et al. (2012). Reduction and oxidation kinetics of nickel-based oxygen-carriers for chemical-looping combustion and chemical-looping reforming. Chem. Eng. J., 188, 142-154, https://doi.org/10.1016/j. cej.2012.01.124.

63. Devi, N. B. et al. (2000). Separation of divalent manganese and cobalt ions from sulphate solutions using sodium salts of D2EHPA, PC 88A and Cyanex 272. Hydrometal., 54(2-3), 117-131, https://doi.org/10.1016/S0304386X(99)00054-7.

64. Nathsarma, K. C. \& Devi, N. (2006). Separation of Zn(II) and Mn(II) from sulphate solutions using sodium salts of D2EHPA, PC88A and Cyanex 272. Hydrometal., 84(3-4),149-154, https://doi.org/10.1016/j. hydromet.2006.05.004.

65. Mohapatra, D. et al. (2007). Liquid-liquid extraction of aluminium(III) from mixed sulphate solutions using sodium salts of Cyanex 272 and D2EHPA. Sep. Purif. Technol., 56(3), 311-318, https://doi.org/10.1016/j. seppur.2007.02.017.

66. Lee, M. S. et al. (2005). Solvent extraction of neodymium ions from hydrochloric acid solution using PC88A and saponified PC88A. Sep. Purif. Technol., 46(1-2), 72-78, https://doi.org/10.1016/j.seppur.2005.04.014.

67. El-Hefny, N. E., El-Nadi, Y. A. \& Daoud, J. A. (2010). Equilibrium and mechanism of samarium extraction from chloride medium using sodium salt of CYANEX 272. Sep. Purif. Technol., 75(3), 310-315, https://doi. org/10.1016/j.seppur.2010.08.020.

68. Reddy, B. R. \& Sharma, B. (2001) Separation of Co and Ni from Sulphate solutions of Indian Ocean nodules using cyanex 272. Miner. Metall. Process., $18,172-178$.

69. Sarangi, K., Reddy, B. R. \& Das, R. P. (1999). Extraction studies of cobalt (II) and nickel (II) from chloride solutions using Na-Cyanex 272: Separation of $\mathrm{Co}(\mathrm{II}) / \mathrm{Ni}(\mathrm{II})$ by the sodium salts of D2EHPA, PC88A and Cyanex 272 and their mixtures. Hydrometal., 52(3), 253-265, https://doi.org/10.1016/ S0304-386X(99)00025-0. 
70. Donia, A. M., Radwan, N. R. E. \& Atina, A. A. (2000). Preparation of mixed $\mathrm{Co}$ and $\mathrm{Cu}$ oxides via thermal decomposition of their oxalates, and study of their catalytic properties. J. Therm. Anal. Calorim., 61(1), 249-261, https:// doi.org/10.1023/A:1010101817256.

71. $\mathrm{Xu}, \mathrm{C}$. et al. (2002). Preparation and characterization of $\mathrm{CuO}$ nanorods by thermal decomposition of $\mathrm{CuC}_{2} \mathrm{O}_{4}$ precursor. Mater. Res. Bull., 37(14), 2365-2372., https://doi.org/10.1016/S0025-5408(02)00848-6

72. Ran, S. et al. (2006). Synthesis, sintering and microstructure of $3 \mathrm{Y}-\mathrm{TZP} /$ CuO nano-powder composites. J. Eur. Ceram. Soc., 26, 391-396, https://doi. org/10.1016/j.jeurceramsoc.2005.07.017.

73. Yoon, J. H. et al. (Eds). (1989). Innovations in materials processing using aqueous, colloid and surface chemistry. Warrendale, PA: TMS.

74. Lee, J. C. \& Doyle, F. M. (1992). Rare earths. Presented in the Proceedings of the International Symposium of Minerals, Metals and Materials Society, Warrendale, PA/San Diego, CA, 139-150.

75. Yoon, J. H. \& Bickert, C. M. (Eds). (1992). Light metals '90. Warrendale, PA: TMS.

76. Sanuki, S. et al. (1994). Precipitation stripping of samarium oxalate from organic solution containing acid type extractant by oxalic acid. Nip. Kinzoku Gakkaishi, 58(11), 1271-1278.

77. Zhang, D. X. et al. (2009). Synthesis and characterisation of nano-composite copper oxalate powders by a surfactant-free stripping-precipitation process. Powder Technol., 189(3), 404-408, https://doi.org/10.1016/j. powtec.2008.06.015.

78. Smirnov, A. L. et al. (2013). Uranium stripping from tri-n-butyl phosphate by hydrogen peroxide solutions. Hydrometal., 137, 18-122, https://doi. org/10.1016/j.hydromet.2013.04.002.

79. Mei, Y. et al. (2012). Preparation and morphology of nano-size ceria by a stripping precipitation using oxalic acid as a precipitating agent. J. Rare Earth, 30(12), 1265-1269, https://doi.org/10.1016/S1002-0721(12)60218-X.

80. Dakshinamoorthy, A. et al. (2008). Separation of palladium from high level liquid waste of PUREX origin by solvent extraction and precipitation methods using oximes. Desalin., 232(1-3), 26-36, https://doi.org/10.1016/j. desal.2007.11.052.

81. El-Hefny, N. E., El-Nadi, Y. A. \& Aly, H. F. (2011). Synthesis and characterization of neodymium phosphate powder resulted from neodymium loaded-HDEHP organic solutions by a stripping-precipitation process using a Lewis type cell. Sep. Purif. Technol., 78(3), 330-335, https://doi. org/10.1016/j.seppur.2011.01.027. 
82. Panja, S. et al. (2012). Uranium(VI) pertraction across a supported liquid membrane containing a branched diglycolamide carrier extractant: Part III: Mass transfer modeling. Desalin., 285, 213-218, https://doi.org/10.1016/j. desal.2011.10.004.

83. Daoud, J. A., Abdel Rahman, N. \& Aly, H. F. (1995). Kinetic separation of uranium from selected fission products. Proceedings of the International Conference on Evaluation of Emerging, Nuclear Fuel Cycle Systems (Global 1995), 11-14 September, Versailles, 1227-1232.

84. Daoud, J. A. \& Aly, H. F. (1996). Kinetic approach for Eu(III) and Am(III) separation using selective thenoyltrifluoroacetone-triphenylarsine oxide systems. Proceedings of the International Solvent Extraction Conference, (ISEC'96), Melbourne, Australia, 19-23 March, 475-480.

85. Grażyna Zakrzewska, T. (2013). Advances in membrane technologies for the treatment of liquid radioactive waste. Desalin., 321, 119-130, https:// doi.org/10.1016/j.desal.2013.02.022.

86. Flouret, J. et al. (2012). Design of an intensified coprecipitation reactor for the treatment of liquid radioactive wastes. Chem. Eng. Sci., 77(30), 176183, https://doi.org/10.1016/j.ces.2012.01.051.

87. El-Didamony, H. et al. (2013). Treatment of phosphogypsum waste produced from phosphate ore processing. J. Hazard. Mater., 244, 596-602, https://doi. org/10.1016/j.jhazmat.2012.10.053.

88. Oleinikova, M. et al. (1999). Selective transport of zinc through activated composite membranes containing di(2-ethylhexyl)dithiophosphoric acid as a carrier. Polyhedr., 18(25), 3353-3359, https://doi.org/10.1016/S02775387(99)00273-9.

89. Urtiaga, A. M. et al. (2000). Comparison of liquid membrane processes for the removal of cadmium from wet phosphoric acid. J. Membr. Sci., 164(12), 229-240, https://doi.org/10.1016/S0376-7388(99)00197-0.

90. Resina, M. et al. (2006). $\mathrm{Zn}(\mathrm{II}), \mathrm{Cd}(\mathrm{II})$ and $\mathrm{Cu}(\mathrm{II})$ separation through organicinorganic hybrid membranes containing di-(2-ethylhexyl) phosphoric acid or di-(2-ethylhexyl) dithiophosphoric acid as a carrier. J. Membr. Sci., 268(1), 57-64, https://doi.org/10.1016/j.memsci.2005.06.008.

91. Negm, M. A., El-Said, N. A. \& Daoud, J. A. (2012). Studies on the use of supported liquid membrane technique for removal of heavy metals from water effluents. Arab. J. Nucl. Sci. Appl., 45(2), 155-168.

92. Choppin, G. R., Liljenzin, J. \& Rydberg, J. (2002). Radiochemistry and nuclear chemistry, 3rd ed. New York: Butterworth-Heinemann.

93. Kupiainen, L., Ahola, J. \& Tanskanen, J. (2011). Kinetics of glucose decomposition in formic acid, Chem. Eng. Res. Des., 89(12), 2706-2713, https://doi.org/10.1016/j.cherd.2011.06.005. 
94. Xiao, X. et al. (2012). Microwave-assisted extraction performed in low temperature and in vacuo for the extraction of labile compounds in food samples. Anal. Chim. Acta, 712, 85-92, https://doi.org/10.1016/j. aca.2011.11.034.

95. Petrov, L. A. et al. (2011). Role of chemical kinetics in the heterogeneous catalysis studies. Chinese J. Cat., 32(6-8), 1085-1112, https://doi. org/10.1016/S1872-2067(10)60225-2.

96. Adnadjevic, B. K. \& Jovanovic, J. D. (2012). A comparative kinetics study on the isothermal heterogeneous acid-catalyzed hydrolysis of sucrose under conventional and microwave heating. J. Mol. Cat. A Chem., 356, 70-7, https://doi.org/10.1016/j.molcata.2011.12.0276.

97. Ma, H. et al. (2012). Kinetics and docking studies on the effect of chemical modification of NADH for redox reactions with dehydrogenases. $J$. Mol. Cat. B Enzym., 77, 111-118, https://doi.org/10.1016/j.molcatb.2012.01.018.

98. Oturan, M. A. et al. (2010). Kinetics of oxidative degradation/mineralization pathways of the phenylurea herbicides diuron, monuron and fenuron in water during application of the electro-Fenton process. Appl. Catal. B Environ., 97(1-2), 82-89, https://doi.org/10.1016/j.apcatb.2010.03.026.

99. Sullivan, R. C., Thornberry, T. \& Abbatt, J. P. D. (2004). Ozone decomposition kinetics on alumina: Effects of ozone partial pressure, relative humidity and repeated oxidation cycles. Atmos. Chem. Phys., 4, 1301-13010, https://doi. org/10.5194/acp-4-1301-2004.

100. Hewes, C. G. \& Davison, R. R. (1971). Kinetics of ozone decomposition and reaction with organics in water. AIChE J., 17(1), 141-147, https://doi. org/10.1002/aic.690170129. 